\title{
Developing a scoring tool to estimate the risk of deterioration for normotensive patients with acute pulmonary embolism on admission
}

\author{
Yizhuo Gao ${ }^{1}$, Chao Ji ${ }^{2}$, Hongyu Zhao ${ }^{3}$, Jun Han $^{3}$, Haitao Shen ${ }^{3}$ and Dong Jia ${ }^{3^{*}}$
}

\begin{abstract}
Background: It is important to identify deterioration in normotensive patients with acute pulmonary embolism (PE). This study aimed to develop a tool for predicting deterioration among normotensive patients with acute PE on admission.

Methods: Clinical, laboratory, and computed tomography parameters were retrospectively collected for normotensive patients with acute PE who were treated at a Chinese center from January 2011 to May 2020 on admission into the hospital. The endpoint of the deterioration was any adverse outcome within 30 days. Eligible patients were randomized 2:1 to derivation and validation cohorts, and a nomogram was developed and validated by the aforementioned cohorts, respectively. The areas under the curves (AUCs) with 95\% confidence intervals (Cls) were calculated. A risk-scoring tool for predicting deterioration was applied as a web-based calculator.

Results: The 845 eligible patients (420 men, 425 women) had an average age of $60.05 \pm 15.43$ years. Adverse outcomes were identified for 81 patients (9.6\%). The nomogram for adverse outcomes included heart rate, systolic pressure, N-terminal-pro brain natriuretic peptide, and ventricle/atrial diameter ratios at 4-chamber view, which provided AUC values of 0.925 in the derivation cohort $(95 \% \mathrm{Cl} 0.900-0.946, p<0.001)$ and 0.900 in the validation cohort $(95 \% \mathrm{Cl}$ 0.883-0.948, $p<0.001$ ). A risk-scoring tool was published as a web-based calculator (https://gaoyzcmu.shinyapps.io/ APE9AD/).
\end{abstract}

Conclusions: We developed a web-based scoring tool that may help predict deterioration in normotensive patients with acute PE.

Keywords: Pulmonary embolism, Computerized tomography, Nomogram, Right ventricle

\section{Background}

In 2019, the European Society of Cardiology (ESC) revised the risk stratification system for patients with acute pulmonary embolism (PE) based on the 2014 ESC guideline [1, 2]. However, 2019 ESC guidelines still

*Correspondence: jiadong0101@126.com

${ }^{3}$ Department of Emergency Medicine, Shengjing Hospital of China Medical University, No. 36, Sanhao Street, Shenyang, China

Full list of author information is available at the end of the article emphasized the critical role of identifying patients with poor prognosis from normotensive patients by the Bova and Fast scores [1]. Furthermore, there are patients with poor prognosis who have shown a false sense of security with normotension at their admission, which might mask the risk of rapid deterioration and death $[3,4]$. Unfortunately, there is no universally recognized tool for distinguishing these patients and guiding clinical decision-making to define the appropriate treatment strategy [1].

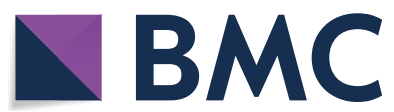

(c) The Author(s) 2021. Open Access This article is licensed under a Creative Commons Attribution 4.0 International License, which permits use, sharing, adaptation, distribution and reproduction in any medium or format, as long as you give appropriate credit to the original author(s) and the source, provide a link to the Creative Commons licence, and indicate if changes were made. The images or other third party material in this article are included in the article's Creative Commons licence, unless indicated otherwise in a credit line to the material. If material is not included in the article's Creative Commons licence and your intended use is not permitted by statutory regulation or exceeds the permitted use, you will need to obtain permission directly from the copyright holder. To view a copy of this licence, visit http://creativecommons.org/licenses/by/4.0/. The Creative Commons Public Domain Dedication waiver (http://creativeco mmons.org/publicdomain/zero/1.0/) applies to the data made available in this article, unless otherwise stated in a credit line to the data. 
Computed tomography (CT) pulmonary angiography can be used to diagnose PE and also can be used for identifying patients who have poor prognosis [5-7]. However, most models for predicting a poor short-term prognosis among normotensive patients with acute PE have not incorporated $\mathrm{CT}$ parameters or only used a CT parameter for identifying right ventricle (RV) dysfunction [3, 8-10]. Different measurement methods and different thresholds in the evaluation of right-toleft heart size by CT caused this discrepancy [11, 12]. Therefore, redefining the ratio of right-to-left heart size parameters from $\mathrm{CT}$ and then combining clinical and laboratory parameters might help promote predictive ability [1].

Although CT parameters regarding cardiac size can reflect an increased impedance in the pulmonary circulation [13]. Individual responses to the right ventricular afterload increase varies broadly depending on comorbidities, associated vasoconstriction, degree of proximal obstruction, and RV straining. These broad variations can be manifested in clinical and laboratory parameters, such as hypotension, tachycardia, myocardial markers and ultrasound RV dysfunction [1]. Based on the 2019 ESC guideline, the present study aimed to develop a semi-quantitative tool that combined clinical, laboratory, and simple CT parameters to promote predictive ability in normotensive patients with acute $\mathrm{PE}$ poor prognosis.

\section{Methods}

\section{Study design}

This retrospective study evaluated clinical, laboratory, and simple CT parameters of normotensive patients with acute PE from admission. The Bova score and 2019 ESC algorithm were used for risk stratification. The outcomes of interest were defined as the occurrence of adverse outcomes within 30 days after admission into hospital. Eligible patients were randomized 2:1 into derivation and validation cohorts. The derivation cohort was used to develop and evaluate a multivariable logistic regression model for predicting the outcomes of interest. The discriminatory power was evaluated by comparing the nomogram to the established risk stratification systems. The consistency of the nomogram was evaluated using the validation cohort. The investigators independently collected the data regarding clinical, laboratory, and CT parameters as well as data regarding the risk stratification scores and outcomes of interest. This research was approved by the Institutional Review Board of the Shengjing Hospital of China Medical University (No. 2020PS522K), and informed consent was exempted due to the absence of treatment intervention in patients.

\section{Patient selection}

Normotensive patients with acute PE were evaluated if they were treated at the Shengjing Hospital of China Medical University between January 2011 and May 2020. The diagnosis and management of acute PE was based on the 2019 ESC guidelines [1]. The inclusion criteria were an age of $\geq 18$ years and a PE diagnosis based on CT pulmonary angiography. The exclusion criteria were pregnancy, reception of reperfusion treatment before admission, and missing data regarding $\mathrm{CT}$ parameters, echocardiography, cardiac troponin I (c-Tn I), and N-terminal-pro brain natriuretic peptide (NT-pro BNP) levels.

\section{Clinical data}

The patients' medical records were reviewed to collect their demographic characteristics and baseline data from their admission regarding heart rate, systolic pressure, history of disease, arterial oxyhemoglobin saturation, c-Tn I concentration $(\mu \mathrm{g} / \mathrm{L})$, and NT-pro BNP concentration $(\mathrm{pg} / \mathrm{mL})$.

\section{Assessing RV dysfunction}

Within $24 \mathrm{~h}$ after admission, RV dysfunction determined a transthoracic echocardiography using an IE Elite ultrasound machine (Philips) equipped with an S 5-1 transducer (frequency conversion 1-5 $\mathrm{MHz}$ ) by ultrasound specialist as following criteria: RV dilation (end-diastolic diameter $>30 \mathrm{~mm}$, evaluated at 4-chamber view or parasternal view), an increased $\mathrm{RV} /$ left ventricle(LV) end-diastolic diameter ratio $>0.9$ at 4-chamber view, hypokinesia of the free RV wall, increased velocity of the jet of tricuspid regurgitation at apical 4-chamber view, decreased tricuspid annulus plane systolic, anyone or combinations of the condition above $[2,14]$.

\section{Risk stratification}

Risk stratification was based on the 2019 ESC algorithm [1] and Bova score [10], with classifications as "low risk," "intermediate-low risk," and "intermediate-high risk" (Additional file 1: Table S1 and Additional file 2: Table S2). The 2019 ESC algorithm evaluated c-Tn I (cutoff: $0.04 \mu \mathrm{g} / \mathrm{L}$ ), NT-pro BNP (cutoff: $600 \mathrm{pg} / \mathrm{mL}$ ) levels, RV dysfunction, and the simple PE severity index [1]. The Bova score was calculated based on c-Tn I (cutoff: $0.05 \mu \mathrm{g} / \mathrm{L}$ ), RV dysfunction, heart rate (cutoff: 110 beats/ min), and systolic pressure (cutoff: $90-100 \mathrm{mmHg}$ ).

\section{Outcomes of interest}

The outcomes of interest were defined as the occurrence of adverse outcomes within 30 days after admission. Adverse outcomes were defined as PE-related deaths, the 
need for mechanical ventilation, the need for cardiopulmonary resuscitation, and the need for life-saving vasopressor and reperfusion treatment $[9,15]$.

\section{Measurement of CT parameters}

Three simple CT parameters were selected for the analysis. The first factor was thrombus location, which was categorized as within the central pulmonary artery (CPA embolism) $[15,16]$, spanning both sides of the bifurcation (saddle-CPA embolism) [17], and outside the CPA (non-CPA embolism) (Additional file 3: Figure S1 a-c). The second factor was the RV and LV diameters in the short-axis plane, which were measured as the maximal diameter from the cardiac intima to the interventricular septum [18], as well as the relative ratio of the RV/LV short-axis diameters (Additional file 4: Figure S2). The third factor was the maximum chamber diameters, which were measured using a 4-chamber view perpendicular to the atrial and interventricular septum (Additional file 4: Figure S2)[6], as well as the relative ratios of the RV/ LV and right atrium (RA)/left atrium (LA) 4-chamber diameters. All CT parameters were measured using the Mimics Medical software (version 19.0, Mimics Medical software, Leuven, Belgium).

\section{Development of the model and risk-scoring tool}

The model was developed based on three steps: (a) identifying relevant prognostic factors; (b) developing and validating the model; (c) evaluating the model's discriminatory power relative to the 2019 ESC algorithm and Bova score.

In the first step, eligible patients were randomized 2:1 into derivation and validation cohorts based on the TRIPOD standard [19]. All clinical, laboratory, and CT parameters were included into a classification and regression tree (CART) to identify relevant prognostic factors with importance [20]. All potential decisional factors for adverse outcomes were evaluated and chosen into splits providing the optimal separations by binomial data until the splits reached a minimum size or no improvement could be made [21]. All the chosen binomial parameters from CART were used to develop the model.

In the second step, univariate and multivariate logistic regression analyses were used to investigate binomial prognostic factors using the derivation cohort, and a nomogram was created by converting each regression coefficient from the multivariate logistic regression onto a scale of 0 points (low) to 100 points (high). The total scores for all variables were summed [22], and the different risk groups were separated based on their total nomogram scores via another CART analysis. A validation cohort was used to evaluate the model's consistency relative to the observed outcomes [21]. A calibration curve was used to assess the consistency between actual incidence and predicted incidence of the nomogram in the derivation and validation cohorts.

In the third step, the models' abilities to predict adverse outcomes were compared to the 2019 ESC algorithm [1] and the Bova score [10] based on the receiver-operating characteristic curve (ROC) and decision curve analysis (DCA). The final risk-scoring tool was published as a free web-based calculator.

\section{Statistical analysis}

Continuous variables were expressed as mean \pm standard deviation and compared using the Student's t test. Categorical variables were presented as numbers (\%) and compared using the $x^{2}$ test. By a recursive partitioning analysis, CART was used to dichotomize each variable while controlling for confounders and divide the derivation cohort into different risk groups according to the total nomogram score [23]. Univariate and multivariate logistic regression analyses were used to evaluate the different factors, and the results were expressed as odds ratios (ORs) with corresponding 95\% confidence intervals (CIs). The nomograms' predictive performances were evaluated based on the concordance index (C-index) and calibration with 1000 bootstrap resampling [22] The ROC curves were used to evaluate sensitivity, specificity, positive predictive value (PPV), negative predictive value (NPV), and the area under the curve (AUC). A calibration curve was used to assess the consistency between the actual incidence and predicted incidence of the nomogram [24]. Clinical utility was evaluated based on net benefit from the DCA. DeLong's test was used to compare AUC values [25]. Differences were considered significant at $p$-values of $<0.05$, and all analyses were performed using $\mathrm{R}$ software (version 4.0.1; R Foundation, https://www.r-project.org).

\section{Results}

\section{Demographics and baseline characteristics}

We evaluated 902 normotensive patients with acute $\mathrm{PE}$, although 57 patients were excluded; a total of 3 patients were excluded due to pregnancy, 5 patients were excluded due to reception of reperfusion treatment, and 49 patients were excluded due to the absence of data on CT parameters, echocardiography, c-Tn I, or NT-pro BNP. Finally, a total of 845 eligible patients were included (Fig. 1), including 420 male patients and 425 female patients with an average age of $60.05 \pm 15.43$ years. Adverse outcomes were identified for 81 patients (42 male and 39 female) who had an average age of $59.36 \pm 15.74$ years (Table 1$)$. No adverse outcomes were identified for 764 patients (378 male and 386 female) who had an average age of $60.12 \pm 15.40$ years. Patients 
902 normotensive patients were selected using the following inclusion criteria:

(1)Diagnosed with acute pulmonary embolism by computed tomography pulmonary angiography (2)Age $\geq 18$ years.

(1) 3 patients due to pregnancy;

(2) 5 patients due to reception of reperfusion treatment before admission;

(3) 49 patients without cardiac tropon in I,N-terminal pro- brain natriuretic

peptide,echocardiography, or computed tomography pulmonary angiography data.

845 normotension patiens with acute pulmonary embolism were included

Random grouping as the ratio of $2: 1$

Derivation cohort $(n=554)$

Validation cohort $(n=291)$

Fig. 1 Flowing chart of inclusion and exclusion criteria

with adverse outcomes had significantly higher values for heart rate, c-Tn I, and NT-pro BNP (all $p<0.001$ ) and had significantly lower value of systolic pressure $(p<0.001)$. Patients with adverse outcomes were more likely to have RV dysfunction $(p<0.001)$. Among CT parameters, patients with adverse outcomes were more likely to have CPA saddle-CPA embolisms (both $p<0.001$ ). Furthermore, patients with adverse outcomes had high values of the RV short-axis diameter, RV 4-chamber diameter, RA 4-chamber diameter, RV/LV short-axis diameter ratio, $\mathrm{RV} / \mathrm{LV}$ 4-chamber diameter ratio, and RA/LA 4-chamber diameter ratio (all $p<0.001$ ). However, patients with adverse outcomes also had lower values for the LV shortaxis diameter, LV 4-chamber diameter, and LA 4-chamber diameter (all $p<0.001$ ).

The Bova score for patients with adverse outcomes revealed low risk (33 patients), intermediate-low risk (17 patients), and intermediate-high risk (31 patients). The Bova score for patients without adverse outcomes revealed low risk (648 patients), intermediate-low risk ( 85 patients), and intermediate-high risk (31 patients). The 2019 ESC algorithm for patients with adverse outcomes revealed low risk (17 patients), intermediate-low risk (14 patients), and intermediate-high risk (50 patients). The 2019 ESC algorithm for patients without adverse outcomes revealed low risk (486 patients), intermediatelow risk (158 patients), and intermediate-high risk (120 patients) (Table 1).

\section{Comparison between derivation and validation cohorts}

After a random grouping with a ratio of 2:1, a total of 554 and 291 patients were divided into derivation and validation cohorts, respectively. In the derivation cohort, the average age was $60.43 \pm 14.95$ years including 267 men and 287 women. In the validation cohort, the average age was $59.32 \pm 16.30$ years including 153 men and 138 women. There was no statistical difference between derivation and validation cohorts (all $p>0.05$ ) (Table 2 ).

\section{Variable selection}

Five variables were considered significant predictors of adverse outcomes and were dichotomized: heart rate $(\geq 110$ beats $/ \mathrm{min}$ vs. $<110$ beats $/ \mathrm{min}$ ), systolic pressure $(90-100 \mathrm{mmHg}$ vs. $>100 \mathrm{mmHg}$ ), NT-pro BNP $(\geq 800 \mathrm{pg} / \mathrm{mL}$ vs. $<800 \mathrm{pg} / \mathrm{mL}), \mathrm{RV} / \mathrm{LV}$ 4-chamber diameter ratio $(\geq 1.25$ vs. $<1.25)$, and RA/LA 4-chamber diameter ratio $(\geq 1.30$ vs. $<1.30)$. A multivariate logistic regression analysis using the derivation cohort revealed that adverse outcomes were independently predicted by heart rate (OR 7.07, 95\% CI 2.92-17.09, 
Table 1 Baseline characteristics among patients with and without adverse outcomes

\begin{tabular}{|c|c|c|c|c|}
\hline & \multirow{2}{*}{$\begin{array}{l}\text { All patients } \\
(n=845)\end{array}$} & \multicolumn{2}{|l|}{ Adverse outcomes } & \multirow[t]{2}{*}{$p$-value } \\
\hline & & Yes $(n=81)$ & No $(n=764)$ & \\
\hline Sex (male) & $420(49.7 \%)$ & $42(51.9 \%)$ & $378(49.5 \%)$ & 0.68 \\
\hline Age (years) & $60.05 \pm 15.43$ & $59.36 \pm 15.74$ & $60.12 \pm 15.40$ & 0.93 \\
\hline Heart rate (beats/min) & $86.57 \pm 17.81$ & $108.64 \pm 22.84$ & $84.23 \pm 15.45$ & $<0.001$ \\
\hline Systolic pressure (mmHg) & $124.33 \pm 18.26$ & $115.22 \pm 19.64$ & $125.30 \pm 17.85$ & $<0.001$ \\
\hline RV dysfunction & $240(28.4 \%)$ & $59(72.8 \%)$ & $181(23.7 \%)$ & $<0.001$ \\
\hline$c-\operatorname{Tn} \mid(\mu \mathrm{g} / \mathrm{L})$ & $0.11 \pm 0.47$ & $0.25 \pm 0.49$ & $0.091 \pm 0.46$ & $<0.001$ \\
\hline NT-pro BNP (pg/mL) & $1,547.12 \pm 3,652.06$ & $131,039 \pm 3,255.93$ & $3,779.92 \pm 5,832.71$ & $<0.001$ \\
\hline CPA embolism & $209(24.7 \%)$ & $45(55.6 \%)$ & $164(22.0 \%)$ & $<0.001$ \\
\hline Saddle-CPA embolism & $62(7.3 \%)$ & $17(21.0 \%)$ & $45(5.9 \%)$ & $<0.001$ \\
\hline RV short-axis diameter (mm) & $39.21 \pm 7.42$ & $44.70 \pm 8.53$ & $38.62 \pm 7.05$ & $<0.001$ \\
\hline LV short-axis diameter (mm) & $40.76 \pm 7.30$ & $33.68 \pm 6.91$ & $41.51 \pm 6.94$ & $<0.001$ \\
\hline RV4-chamber diameter (mm) & $36.38 \pm 7.37$ & $42.64 \pm 10.28$ & $35.72 \pm 6.67$ & $<0.001$ \\
\hline LV 4-chamber diameter (mm) & $39.47 \pm 7.36$ & $31.63 \pm 7.09$ & $40.30 \pm 6.88$ & $<0.001$ \\
\hline RA 4-chamber diameter (mm) & $45.44 \pm 9.34$ & $52.38 \pm 11.72$ & $44.70 \pm 8.74$ & $<0.001$ \\
\hline LA 4-chamber diameter (mm) & $34.83 \pm 8.52$ & $29.18 \pm 8.00$ & $35.43 \pm 8.35$ & $<0.001$ \\
\hline RV/LV short-axis diameter ratio & $1.00 \pm 0.30$ & $1.38 \pm 0.40$ & $0.96 \pm 0.25$ & $<0.001$ \\
\hline RV/LV 4-chamber diameter ratio & $0.96 \pm 0.31$ & $1.44 \pm 0.59$ & $0.90 \pm 0.20$ & $<0.001$ \\
\hline RA/LA 4-chamber diameter ratio & $1.39 \pm 0.52$ & $1.97 \pm 0.87$ & $1.33 \pm 0.42$ & $<0.001$ \\
\hline \multicolumn{5}{|l|}{ Bova score } \\
\hline Low risk & $681(75.9 \%)$ & $33(40.7 \%)$ & $648(84.4 \%)$ & $<0.001$ \\
\hline Intermediate-low risk & $102(12.1 \%)$ & $17(20.7 \%)$ & $85(11.1 \%)$ & 0.009 \\
\hline Intermediate-high risk & $62(7.3 \%)$ & $31(38.3 \%)$ & $31(4.1 \%)$ & $<0.001$ \\
\hline \multicolumn{5}{|l|}{2019 ESC algorithm } \\
\hline Low risk & $503(59.5 \%)$ & $17(21.0 \%)$ & $486(63.6 \%)$ & $<0.001$ \\
\hline Intermediate-low risk & $172(20.4 \%)$ & $14(17.3 \%)$ & $158(20.7 \%)$ & 0.47 \\
\hline Intermediate-high risk & $170(20.1 \%)$ & $50(61.7 \%)$ & $120(15.7 \%)$ & $<0.001$ \\
\hline
\end{tabular}

CTn-I cardiac troponin I, NT-pro BNP N-terminal pro-brain natriuretic peptide, CPA central pulmonary artery, $R V$ right ventricle, $L V$ left ventricle, $R A$ right atrium, $L A$ left atrium, ESC European Society of Cardiology

$p<0.001$ ), systolic pressure (OR 7.68, 95\% CI 1.57$37.58, p<0.001$ ), NT-pro BNP (OR 3.35, 95\% CI 1.369.17, $p<0.001$ ), RA/LA 4-chamber diameter ratio (OR 3.53, 95\% CI 1.27-2.85, $p<0.001$ ), and RV/LV 4-chamber diameter ratio (OR 29.86, 95\% CI 11.34-78.61, $p<0.001$ ) (Table 3).

\section{Performance of the nomograms in the derivation and validation cohorts}

Nomograms were developed using the two multivariate logistic regression models (Fig. 2). The nomogram for predicting adverse outcomes incorporated five variables and provided good $\mathrm{C}$-index values in the derivation (C-index: $0.925,95 \%$ CI 0.900-0.946) and validation cohorts (C-index: 0.900, 95\% CI 0.883-0.948) (Fig. 3). The calibration curve also revealed good agreement between the nomogram's predictions and the actual outcomes (Fig. 4).

\section{Predicting adverse outcomes based on the nomogram, Bova score, and 2019 ESC algorithm}

The AUC values for predicting adverse outcomes were 0.925 for the nomogram (95\% CI $0.900-0.946, p<0.001)$, 0.797 for the Bova score (95\% CI 0.761-0.830, $p<0.001$ ), and 0.790 for the 2019 ESC algorithm (95\% CI 0.7530.823, $p<0.001)$. Comparing the nomogram and Bova score revealed a difference in AUC values of 0.128 (95\% CI $0.072-0.184, p<0.001)$. A comparison of the nomogram and 2019 ESC algorithm revealed a difference in AUC values of 0.136 (95\% CI $0.075-0.196, p<0.001$ ). The nomogram had a higher PPV for predicting adverse outcomes (66.5\%) than did the Bova score $(34.8 \%)$ or the 2019 ESC algorithm (31.3\%) (Table 4).

The DCA revealed that the nomogram had greater net benefit than the 2019 ESC algorithm or the Bova score for predicting adverse outcomes. Using the nomogram for predicting adverse outcomes added a net benefit of 0.03-0.98 (Fig. 5). 
Table 2 Comparation between derivation and validation cohorts

\begin{tabular}{|c|c|c|c|}
\hline & $\begin{array}{l}\text { Derivation cohort } \\
(n=554)\end{array}$ & $\begin{array}{l}\text { Validation cohort } \\
(n=291)\end{array}$ & $p$-value \\
\hline Sex (male) & $267(48.2 \%)$ & $153(52.6 \%)$ & 0.23 \\
\hline Age (years) & $60.43 \pm 14.95$ & $59.32 \pm 16.30$ & 0.33 \\
\hline Heart rate (beats/min) & $86.11 \pm 17.76$ & $87.46 \pm 17.89$ & 0.30 \\
\hline Systolic pressure (mmHg) & $126.92 \pm 18.27$ & $125.30 \pm 18.09$ & 0.22 \\
\hline RV dysfunction & $161(29.0 \%)$ & $79(27.1 \%)$ & 0.56 \\
\hline$c-T n$ I $(\mu \mathrm{g} / L)$ & $0.11 \pm 0.54$ & $0.10 \pm 0.29$ & 0.79 \\
\hline NT-pro BNP (pg/mL) & $1638.25 \pm 3958.77$ & $1373.61 \pm 2980.96$ & 0.28 \\
\hline CPA embolism & $141(25.5 \%)$ & $68(23.4 \%)$ & 0.50 \\
\hline Saddle-CPA embolism & $38(6.9 \%)$ & $24(8.2 \%)$ & 0.46 \\
\hline RV short-axis diameter (mm) & $39.26 \pm 7.605$ & $39.11 \pm 6.97$ & 0.77 \\
\hline LV short-axis diameter (mm) & $40.58 \pm 7.65$ & $41.08 \pm 7.52$ & 0.35 \\
\hline RV4-chamber diameter (mm) & $36.22 \pm 7.21$ & $36.68 \pm 7.68$ & 0.41 \\
\hline LV 4-chamber diameter (mm) & $39.50 \pm 7.26$ & $39.41 \pm 7.55$ & 0.86 \\
\hline RA 4-chamber diameter (mm) & $45.50 \pm 9.38$ & $45.32 \pm 9.27$ & 0.79 \\
\hline LA 4-chamber diameter (mm) & $34.95 \pm 8.38$ & $34.61 \pm 8.77$ & 0.58 \\
\hline RV/LV short-axis diameter ratio & $1.00 \pm 0.31$ & $0.98 \pm 0.27$ & 0.34 \\
\hline RV/LV 4-chamber diameter ratio & $0.95 \pm 0.28$ & $0.97 \pm 0.35$ & 0.37 \\
\hline RA/LA 4-chamber diameter ratio & $1.39 \pm 0.52$ & $1.40 \pm 0.51$ & 0.76 \\
\hline \multicolumn{4}{|l|}{ Bova score } \\
\hline Low risk & $445(80.3 \%)$ & $236(81.1 \%)$ & 0.79 \\
\hline Intermediate-low risk & $66(11.9 \%)$ & $36(12.3 \%)$ & 0.85 \\
\hline Intermediate-high risk & $43(7.8 \%)$ & $19(6.5 \%)$ & 0.51 \\
\hline \multicolumn{4}{|l|}{2019 ESC algorithm } \\
\hline Low risk & $330(59.6 \%)$ & $173(59.5 \%)$ & 0.97 \\
\hline Intermediate-low risk & $112(20.2 \%)$ & $60(20.6 \%)$ & 0.89 \\
\hline Intermediate-high risk & $112(20.2 \%)$ & $58(19.9 \%)$ & 0.92 \\
\hline Adverse outcomes & $54(9.7 \%)$ & $27(9.3 \%)$ & 0.83 \\
\hline
\end{tabular}

$C T n$ - I cardiac troponin I, NT-pro BNP N-terminal pro-brain natriuretic peptide, CPA central pulmonary artery, $R V$ right ventricle, $L V$ left ventricle, $R A$ right atrium, $L A$ left atrium, ESC European Society of Cardiology

Table 3 Univariate and multivariate logistic regression analyses for developing the nomogram to predict adverse outcomes in the derivation cohort

\begin{tabular}{|c|c|c|c|c|}
\hline & \multicolumn{2}{|l|}{ Univariate analysis } & \multicolumn{2}{|l|}{ Multivariate analysis } \\
\hline & OR $(95 \% \mathrm{Cl})$ & $p$-value & OR $(95 \% \mathrm{Cl})$ & $p$-value \\
\hline Heart rate ( $\geq 110$ vs. $<110$ beats/min) & $20.58(10.77-39.33)$ & $<0.001$ & $7.07(2.92-17.09)$ & $<0.001$ \\
\hline Systolic pressure (90-100 vs.>100 mmHg) & $26.11(9.43-72.28)$ & $<0.001$ & $7.68(1.57-37.58)$ & 0.012 \\
\hline NT-pro BNP ( $\geq 800$ vs. $<800$ pg/mL) & $7.94(4.07-15.50)$ & $<0.001$ & $3.35(1.39-8.11)$ & 0.0073 \\
\hline RV/LV 4-chamber diameter ratio ( $\geq 1.25$ vs. $<1.25)$ & $64.66(28.84-144.96)$ & $<0.001$ & $29.86(11.34-78.61)$ & $<0.001$ \\
\hline RA/LA 4-chamber diameter ratio ( $\geq 1.30$ vs. < 1.30) & $6.63(3.17-13.85)$ & $<0.001$ & $3.53(1.36-9.17)$ & 0.0096 \\
\hline
\end{tabular}

NT-pro BNP N-terminal pro-brain natriuretic peptide; $R V$ right ventricle; $L V$ left ventricle; $R A$ right atrium; $L A$ left atrium; $O R$ odds ratio; $C l$ confidence interval

\section{Development of the risk-scoring tool}

The nomogram for predicting adverse outcomes was used to develop a web-based calculator (https://gaoyz cmu.shinyapps.io/APE9AD/), which assigned patients to a high-risk group ( $\geq 145$ points) or a low-risk group ( $<145$ points). The QR code in the lower right corner of each calculator in Fig. 6 can be used to publish the results to mobile electronic equipment. 


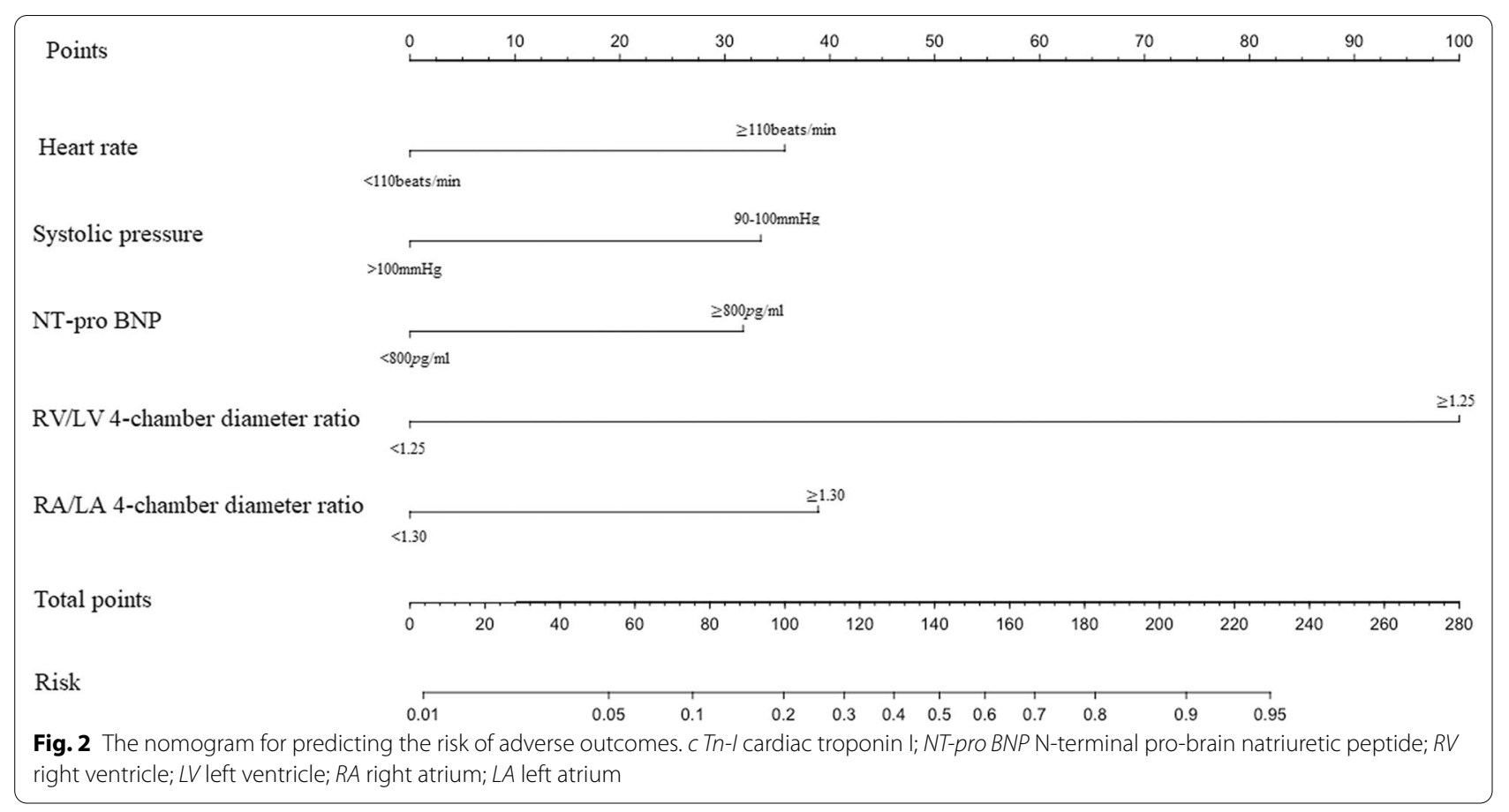

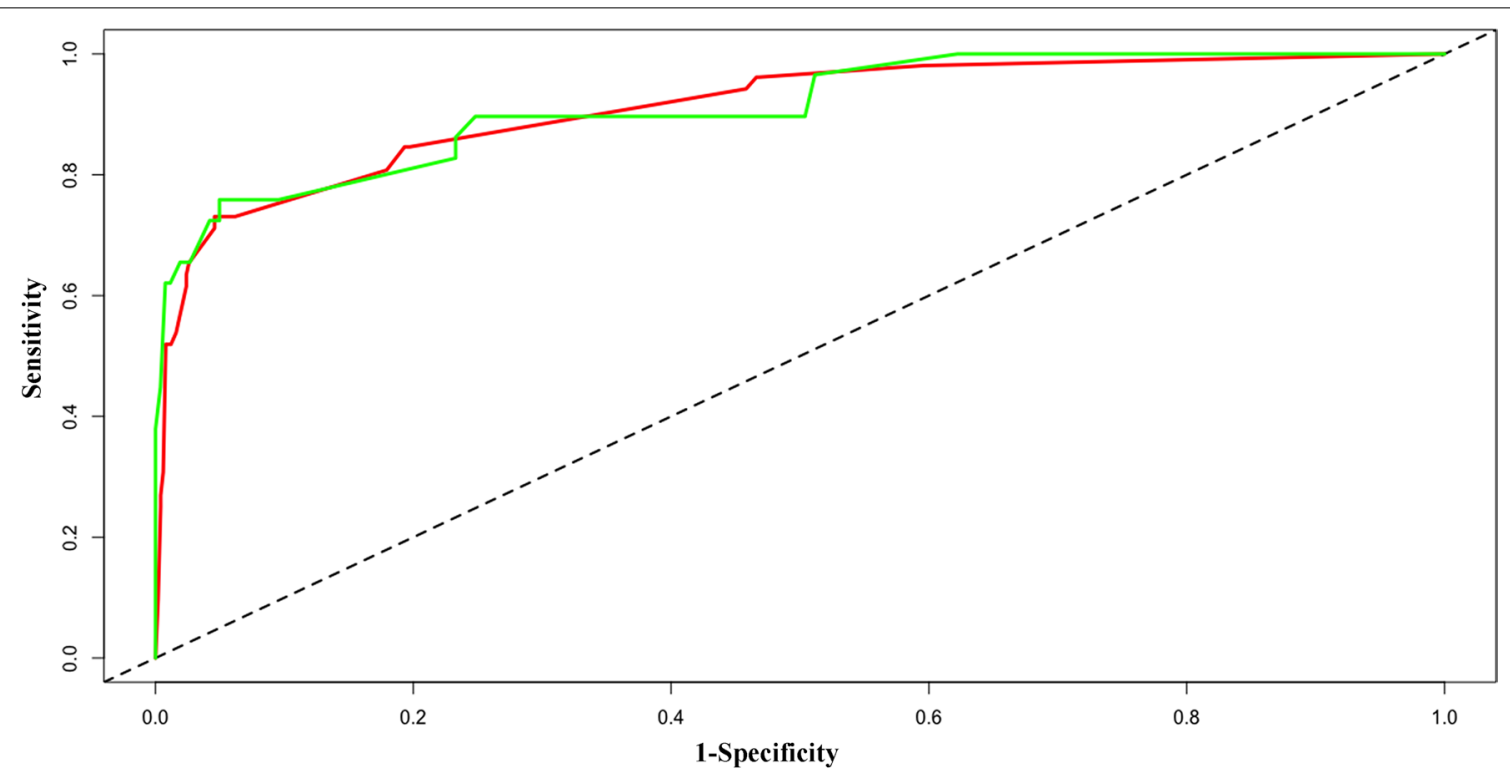

Fig. 3 The receiver-operating characteristic curves for predicting adverse outcomes. The training dataset is shown using the red line and the validation dataset is shown using the green line. The area under the curve values for predicting adverse outcomes were 0.925 in the training dataset ( $95 \%$ confidence interval [Cl] $0.900-0.946, p<0.001)$ and 0.900 in the validation dataset $(95 \% \mathrm{Cl} 0.883-0.948, p<0.001)$

\section{Discussion}

This study developed a tool for estimating the risk of deterioration among normotensive patients with acute PE. Results revealed that the risk of adverse outcomes within the first 30 days after admission could be predicted using a nomogram that incorporated the RV/ LV and RA/LA 4-chamber diameter ratios, NT-pro BNP concentration, systolic pressure, and heart rate. Furthermore, this risk-scoring tool had better discriminatory power and a greater net benefit than did the 2019 ESC 


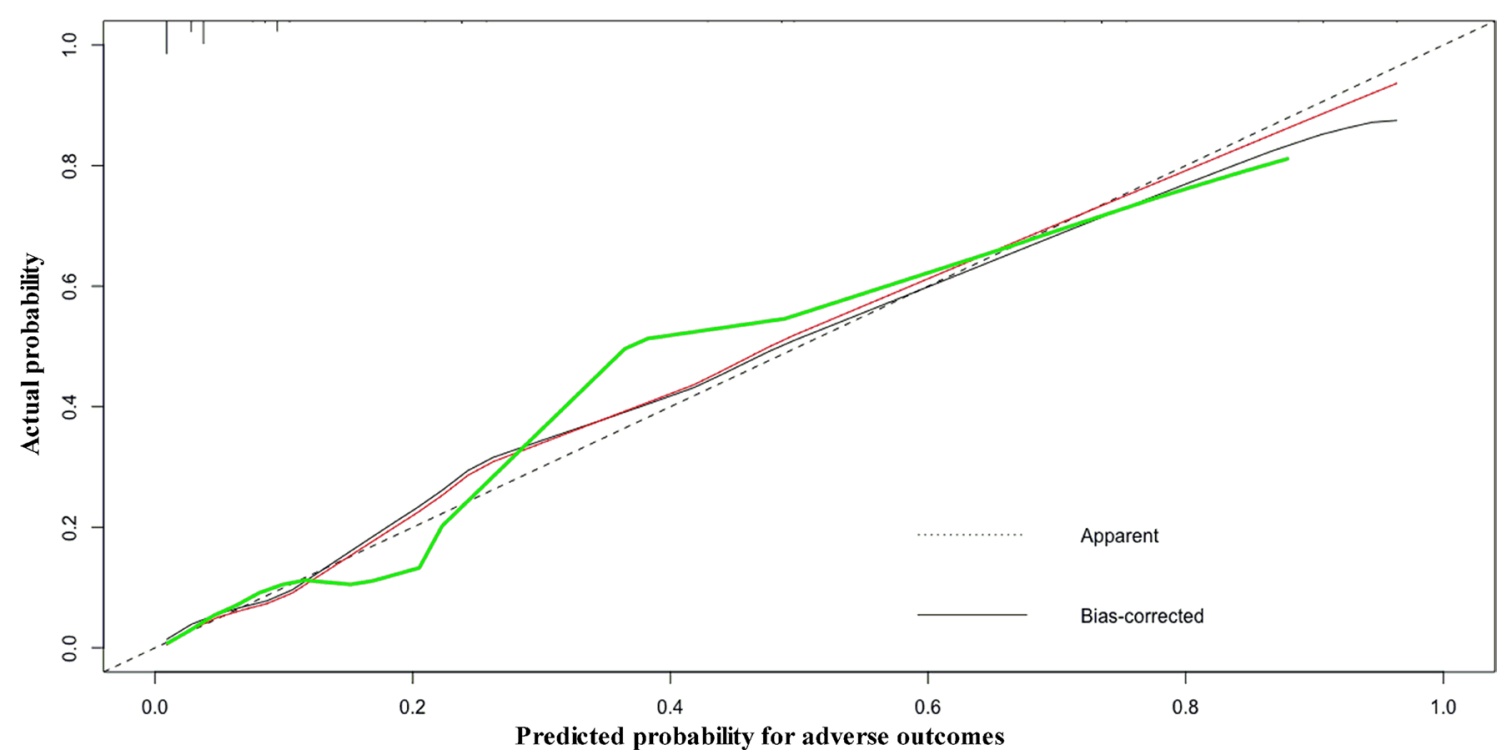

Fig. 4 Calibration curves for the nomogram predicting adverse outcomes. The training dataset is shown using the red line, and the validation dataset is shown using the green line

Table 4 Comparing the nomogram to risk stratification for adverse outcomes

\begin{tabular}{|c|c|c|c|c|c|}
\hline & AUC $(95 \% \mathrm{Cl})$ & $\begin{array}{l}\text { Sensitivity } \\
\text { (\%) }\end{array}$ & Specificity (\%) & $\begin{array}{l}\text { PPV } \\
\text { (\%) }\end{array}$ & $\begin{array}{l}\text { NPV } \\
\text { (\%) }\end{array}$ \\
\hline Nomogram & $0.925(0.900-0.946)$ & 74.1 & 95.1 & 65.5 & 97.2 \\
\hline Bova score & $0.797(0.761-0.830)$ & 70.4 & 85.8 & 34.8 & 96.4 \\
\hline 2019 ESC algorithm & $0.790(0.753-0.823)$ & 64.8 & 84.6 & 31.3 & 95.7 \\
\hline
\end{tabular}

ESC European Society of Cardiology, AUC area under the curve, $P P V$ positive predictive value, NPV negative predictive value, $C l$ confidence interval

algorithm and the Bova score. Finally, this tool was converted into convenient web-based calculators that could be used in clinical practice.

Our results are consistent with the Bova score as a decreased systolic pressure (90-100 $\mathrm{mmHg}$ ) and an elevated heart rate $(\geq 110$ beats/min) were risk factors for adverse outcomes. In normotensive patients with acute PE that is deteriorating, the presentation of lower systolic pressure together with more tachycardia are warning of overt RV dysfunction [26] and are associated with the poor short-term prognosis in acute PE [1, 27]. However, we found some differences that elevated NT-pro BNP concentration was included in the final scoring tool for predicting adverse outcomes, and c-Tn I concentration was not included. c-Tn I was still one of the important predictors of adverse outcomes in patients with acute PE $[1,10]$. Based on the CART analysis that selected variables that were most likely to identify adverse outcomes [28], c-Tn I might not have had enough importance compared to the other parameters in our study. In some previous studies, the elevated c-Tn I was also not included after a multifactor analysis [29, 30]. NT-pro BNP reflected RV strain, which was complementary and not mutually exclusive to CT parameters [29]. This might be the reason that the NT-pro BNP, not c-Tn I, was included into the final model in our study.

Interestingly, the increased predictive value of our risk-scoring tool (vs. the 2019 ESC algorithm and the Bova score) was mainly related to the RV/LV and RA/ LA 4-chamber diameter ratios. A previous report had described the interaction between the RV and LV via the interventricular septum [31], and the RV and pulmonary circulation are characterized by low impedance and high output [11]. Furthermore, the size of the LV is larger than the size of the RV. Thus, severe PE leads to increased pressure in the $R V$, which compresses the LV via the interventricular septum, and clear RV-to-LV compression can be observed in cases with severe chronic pulmonary hypertension $(\mathrm{PH})$ [32]. Severe $\mathrm{PH}$ is also the main pathophysiological mechanism underlying the occurrence of adverse outcomes in acute PE [1]. Decreased blood return to the LV also further reduces LV size, which 


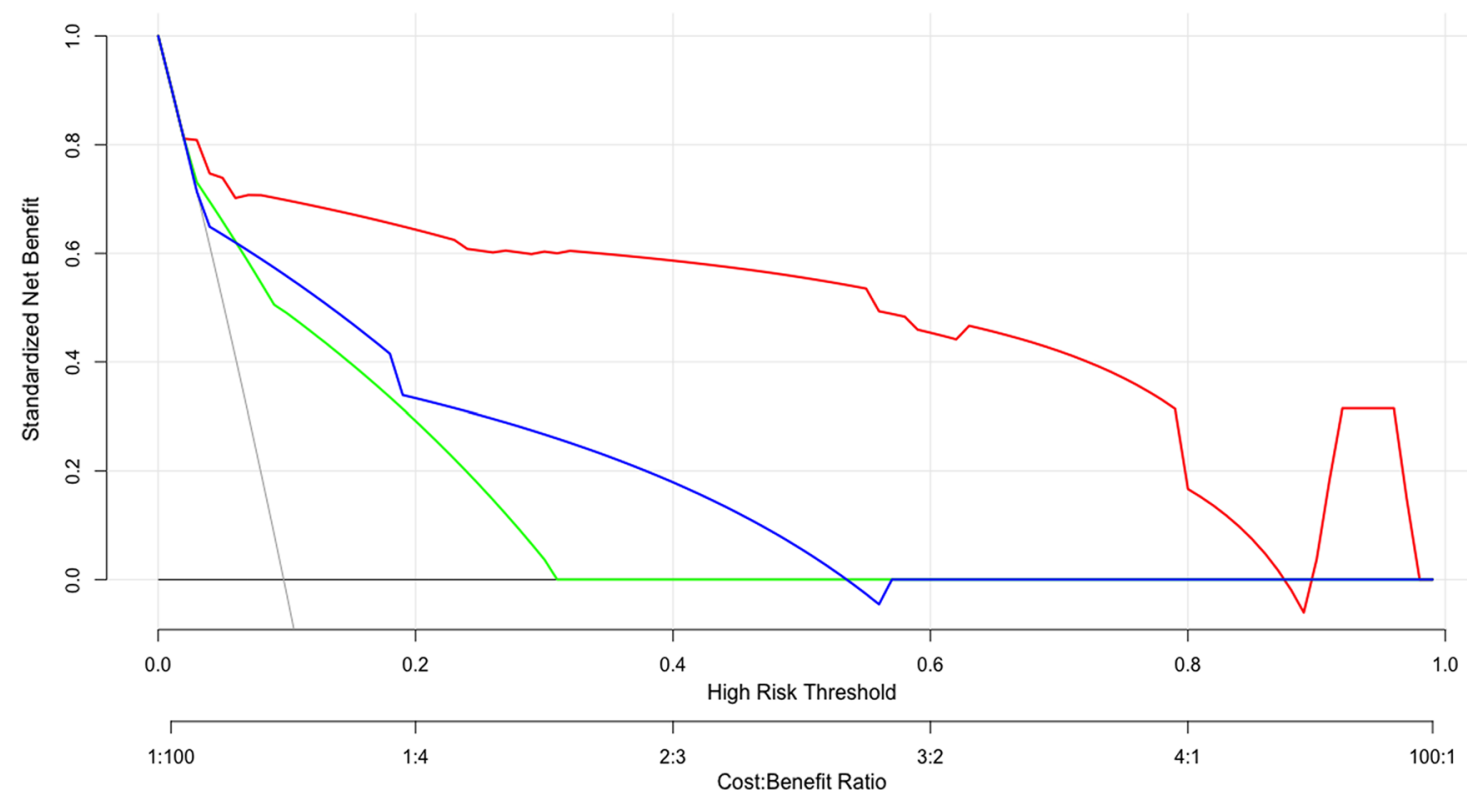

Fig. 5 Decision curve analysis for the nomogram. A comparison of net benefit between the nomogram, the 2019 ESC algorithm, and the Bova score, which revealed that the nomogram was better in terms of net benefit (net benefit: 0.03-0.98). The nomogram is shown using the red line, Bove score is shown using the green line, and 2019 ESC algorithm is shown using green line. ESC European Society of Cardiology

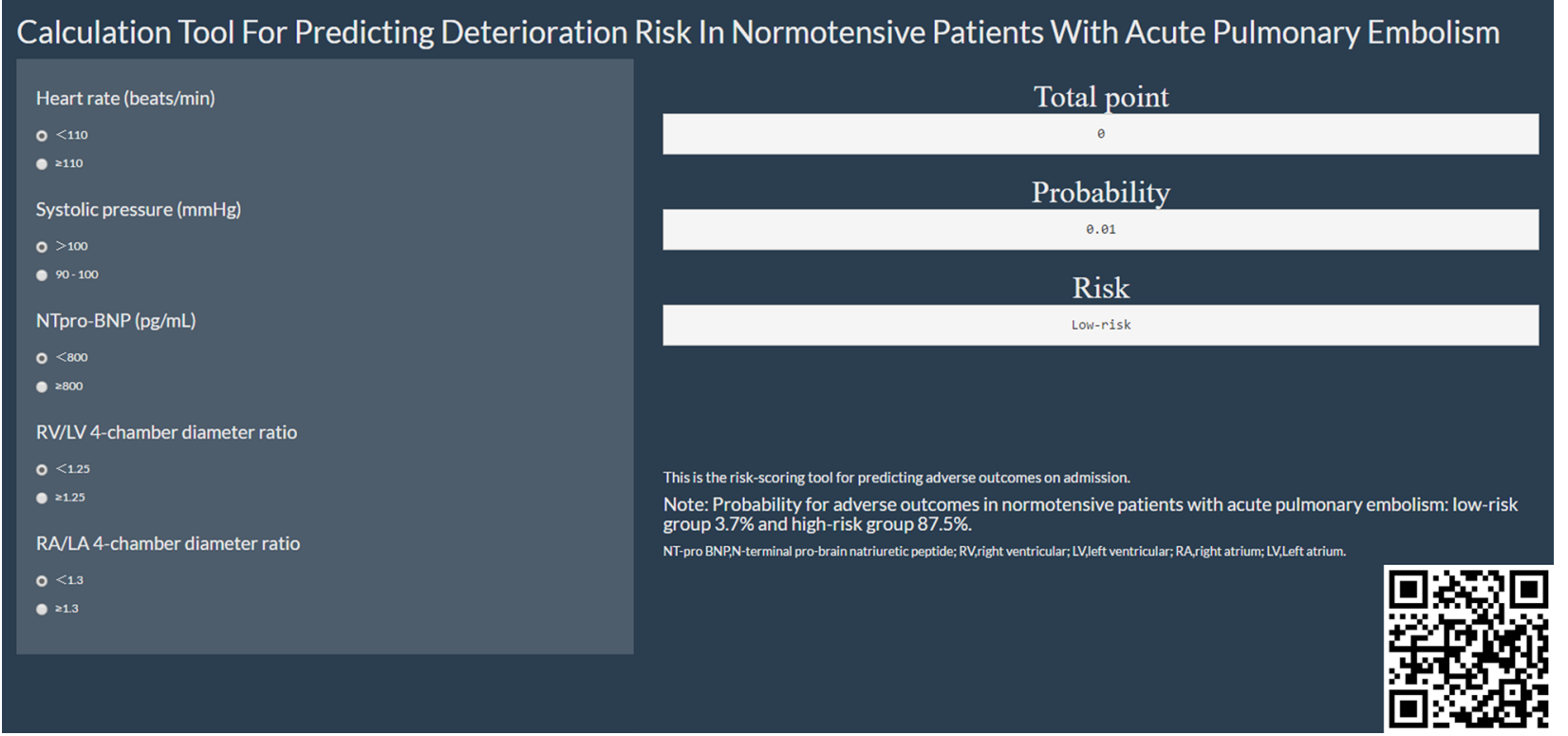

Fig. 6 The web-based calculator for estimating the risk of adverse outcomes (https://gaoyzcmu.shinyapps.io/APE9AD/). The QR code in the lower right corner can be used to publish the result to mobile electronic equipment. NT-pro BNP N-terminal pro-brain natriuretic peptide; $R V$ right ventricle; $L V$ left ventricle; $R A$ right atrium; $L A$ left atrium

leads to an increased right-to-left heart size ratio. The four-chamber view is defined as the plane perpendicular to the atrial and interventricular septum [6], which can be used to accurately evaluate the increased size of the right heart, the decreased size of the left heart, and the interaction between these factors. The threshold value in our study was an RV/LV 4-chamber diameter ratio of 1.25 , rather than previously reported cutoffs of $0.9,1.0$, or 1.1 [33,34], although differences in the definition of this threshold may explain the selection of different 
parameters between our study and previous studies. The RA/LA 4-chamber diameter ratio was another factor in our risk-scoring tool. The membranous structure [31] and greater pressure sensitivity of the atrium (vs. the ventricle) may explain the lower weighting of the RA/LA 4-chamber diameter ratio relative to the weighting of the $\mathrm{RV} / \mathrm{LV}$ 4-chamber diameter ratio in our scoring tool.

\section{Limitations}

The present study has several limitations that should be considered. First, although we evaluated data from normotensive patients with acute PE who were treated during an approximately 10 -year period, the retrospective analysis is prone to bias. Second, although this scoring tool was developed using randomized derivation and validation cohorts, external validation is also required. Third, we did not have access to data regarding cardiac troponin $\mathrm{T}$, and heart type fatty acid binding protein, which precluded comparisons of our tools to the fast prognostic score [9] for predicting adverse outcomes.

\section{Conclusion}

We developed a scoring tool that was published as webbased calculators for predicting adverse outcomes among normotensive patients with acute PE. This risk-scoring tool may help improve the management of patients with acute $\mathrm{PE}$ by predicting deterioration.

\section{Supplementary Information}

The online version contains supplementary material available at https://doi. org/10.1186/s12931-020-01602-x.

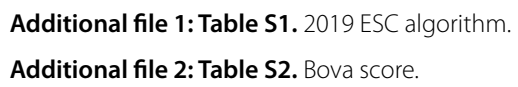

\section{Abbreviations}

ESC: European Society of Cardiology; PE: Pulmonary embolism; CT: Computed tomography; C-Tn I: Cardiac troponin I; NT-pro BNP: N-terminal pro-brain natriuretic peptide; RV: Right ventricle; LV: Left ventricle; RA: Right atrium; LA: Left atrium; CPA: Central pulmonary artery; CART: Classification and regression tree; ROC: Receiver-operating characteristic curve; AUC: Area under the curve; OR: Odds ratio; Cl: Confidence interval; PPV: Positive predictive value; NPV: Negative predictive value; DCA: Decision curve analysis; C-index: Concordance index; PH: Pulmonary hypertension.

\section{Acknowledgements}

This article accepted professional language-editing service.

\section{Authors' contributions}

All the authors read and approved the final manuscript. DJ designed, performed the research and measurement $C T$ parameters as well as wrote the manuscript; YG evaluated the endpoints and performed statistical analysis; CJ performed the statistical analysis; JH collected the clinal parameters. $\mathrm{HZ}$ collected the laboratory parameters; HS conducted the risk stratification.
Funding

This study received funding from the 345 Talent Project of Shengjing Hospital of China Medical University and Health commission of Liaoning (LNCCC-D12-2015).

\section{Availability of data and materials}

The datasets used and/or analyzed during the current study are available from the corresponding author on reasonable request.

\section{Ethics approval and consent to participate}

This research was approved by the Institutional review board of Shengjing Hospital of China Medical University (No.2020PS522K). Patient confidentiality was maintained.

\section{Consent for publication}

Not applicable.

\section{Competing interests}

The authors declare that they have no competing interests.

\begin{abstract}
Author details
1 Department of Pulmonary and Critical Care Medicine, Shengjing Hospital of China Medical University, No. 36, Sanhao Street, Shenyang, China. ${ }^{2}$ Department of Clinical Epidemiology, Shengjing Hospital of China Medical University, No. 36, Sanhao Street, Shenyang, China. ${ }^{3}$ Department of Emergency Medicine, Shengjing Hospital of China Medical University, No. 36, Sanhao Street, Shenyang, China.
\end{abstract}

Received: 28 July 2020 Accepted: 14 December 2020 Published online: 06 January 2021

\section{References}

1. Konstantinides SV, Meyer G, Becattini C, Bueno H, Geersing GJ, Harjola VP, Huisman MV, Humbert M, Jennings CS, Jimenez D, et al. 2019 ESC Guidelines for the diagnosis and management of acute pulmonary embolism developed in collaboration with the European Respiratory Society (ERS): the Task Force for the diagnosis and management of acute pulmonary embolism of the European Society of Cardiology (ESC). Eur Respir J. 2019;54:1901647.

2. Konstantinides SV, Torbicki A, Agnelli G, Danchin N, Fitzmaurice D, Galie N, Gibbs JS, Huisman MV, Humbert M, Kucher N, et al. 2014 ESC guidelines on the diagnosis and management of acute pulmonary embolism. Eur Heart J. 2014;35:3033-69, 3069a-69k.

3. Vedovati MC, Cimini LA, Pierpaoli L, Vanni S, Cotugno M, Pruszczyk P, Di Filippo F, Stefanone V, Torrecillas LG, Kozlowska M, et al. Prognostic value of respiratory index in haemodynamically stable patients with acute pulmonary embolism: the Respiratory Index model study. Eur Heart J Acute Cardiovasc Care. 2020. https://doi.org/10.1177/2048872620925253.

4. Lyhne MD, Schultz JG, Kramer A, Mortensen CS, Nielsen-Kudsk JE, Andersen A. Right ventricular adaptation in the critical phase after acute intermediate-risk pulmonary embolism. Eur Heart J Acute Cardiovasc Care. 2020. https://doi.org/10.1177/2048872620925253.

5. Kang DK, Thilo C, Schoepf UJ, Barraza JM Jr, Nance JW Jr, Bastarrika G, Abro JA, Ravenel JG, Costello P, Goldhaber SZ. CT signs of right ventricular dysfunction: prognostic role in acute pulmonary embolism. JACC Cardiovasc Imaging. 2011;4:841-9.

6. Lu MT, Demehri S, Cai T, Parast L, Hunsaker AR, Goldhaber SZ, Rybicki FJ. Axial and reformatted four-chamber right ventricle-to-left ventricle diameter ratios on pulmonary $\mathrm{CT}$ angiography as predictors of death after acute pulmonary embolism. AJR Am J Roentgenol. 2012;198:1353-60.

7. Beenen LFM, Bossuyt PMM, Stoker J, Middeldorp S. Prognostic value of cardiovascular parameters in computed tomography pulmonary angiography in patients with acute pulmonary embolism. Eur Respir J. 2018;52:1702611.

8. Jimenez D, Kopecna D, Tapson V, Briese B, Schreiber D, Lobo JL, Monreal M, Aujesky D, Sanchez O, Meyer G, et al. Derivation and validation of multimarker prognostication for normotensive patients with acute symptomatic pulmonary embolism. Am J Respir Crit Care Med. 2014;189:718-26. 
9. Hobohm L, Becattini C, Konstantinides SV, Casazza F, Lankeit M. Validation of a fast prognostic score for risk stratification of normotensive patients with acute pulmonary embolism. Clin Res Cardiol. 2020. https://doi. org/10.1007/s00392-019-01593-w.

10. Fernandez C, Bova C, Sanchez O, Prandoni P, Lankeit M, Konstantinides S, Vanni S, Fernandez-Golfin C, Yusen RD, Jimenez D. Validation of a model for identification of patients at intermediate to high risk for complications associated with acute symptomatic pulmonary embolism. Chest. 2015;148:211-8.

11. Pinsky MR. The right ventricle: interaction with the pulmonary circulation. Crit Care. 2016;20:266

12. Meinel FG, Nance JW Jr, Schoepf UJ, Hoffmann VS, Thierfelder KM, Costello P, Goldhaber SZ, Bamberg F. Predictive value of computed tomography in acute pulmonary embolism: systematic review and meta-analysis. Am J Med. 2015;128(747-759):e742.

13. Bax S, Jacob J, Ahmed R, Bredy C, Dimopoulos K, Kempny A, Kokosi M, Kier G, Renzoni E, Molyneaux PL, et al. Right ventricular to left ventricular ratio at $\mathrm{CT}$ pulmonary angiogram predicts mortality in interstitial lung disease. Chest. 2020;157:89-98.

14. Jaff MR, McMurtry MS, Archer SL, Cushman M, Goldenberg N, Goldhaber SZ, Jenkins JS, Kline JA, Michaels AD, Thistlethwaite P, et al. Management of massive and submassive pulmonary embolism, iliofemoral deep vein thrombosis, and chronic thromboembolic pulmonary hypertension. Circulation. 2011;123:1788-830.

15. Jia D, Li XL, Zhang Q, Hou G, Zhou XM, Kang J. A decision tree built with parameters obtained by computed tomographic pulmonary angiography is useful for predicting adverse outcomes in non-high-risk acute pulmonary embolism patients. Respir Res. 2019;20:187.

16. Barker AJ, Roldan-Alzate A, Entezari P, Shah SJ, Chesler NC, Wieben O, Markl M, Francois CJ. Four-dimensional flow assessment of pulmonary artery flow and wall shear stress in adult pulmonary arterial hypertension: results from two institutions. Magn Reson Med. 2015;73:1904-13.

17. Zuin M, Rigatelli G, Zonzin P, Casazza F, Roncon L. Saddle pulmonary embolism in hemodynamically stable patients: to lyse or not to lyse? An issue in no guidelines land. Eur J Intern Med. 2017;46:e26-8.

18. Aribas A, Keskin S, Akilli H, Kayrak M, Erdogan HI, Guler I, Yildirim O, Bekci $\mathrm{TT}$. The use of axial diameters and CT obstruction scores for determining echocardiographic right ventricular dysfunction in patients with acute pulmonary embolism. Jpn J Radiol. 2014;32:451-60.

19. Moons KG, Altman DG, Reitsma JB, loannidis JP, Macaskill P, Steyerberg EW, Vickers AJ, Ransohoff DF, Collins GS. Transparent reporting of a multivariable prediction model for Individual Prognosis or Diagnosis (TRIPOD): explanation and elaboration. Ann Intern Med. 2015;162:W1-73.

20. Langendijk JA, Slotman BJ, van der Waal I, Doornaert P, Berkof J, Leemans CR. Risk-group definition by recursive partitioning analysis of patients with squamous cell head and neck carcinoma treated with surgery and postoperative radiotherapy. Cancer. 2005;104:1408-17.

21. Wolff RF, Moons KGM, Riley RD, Whiting PF, Westwood M, Collins GS, Reitsma JB, Kleijnen J, Mallett S, Groupdagger P. PROBAST: a tool to assess the risk of bias and applicability of prediction model studies. Ann Intern Med. 2019;170:51-8.

22. Lei Z, Li J, Wu D, Xia Y, Wang Q, Si A, Wang K, Wan X, Lau WY, Wu M, Shen F. Nomogram for preoperative estimation of microvascular invasion risk in hepatitis B virus-related hepatocellular carcinoma within the Milan criteria. JAMA Surg. 2016;151:356-63.

23. Aviram G, Soikher E, Bendet A, Shmueli H, Ziv-Baran T, Amitai Y, Friedensohn L, Berliner S, Meilik A, Topilsky Y. Prediction of mortality in pulmonary embolism based on left atrial volume measured on CT pulmonary angiography. Chest. 2016;149:667-75.

24. Wu S, Zheng J, Li Y, Yu H, Shi S, Xie W, Liu H, Su Y, Huang J, Lin T. A radiomics nomogram for the preoperative prediction of lymph node metastasis in bladder cancer. Clin Cancer Res. 2017;23:6904-11.

25. DeLong ER, DeLong DM, Clarke-Pearson DL. Comparing the areas under two or more correlated receiver operating characteristic curves: a nonparametric approach. Biometrics. 1988;44:837-45.

26. Grifoni S, Olivotto I, Cecchini P, Pieralli F, Camaiti A, Santoro G, Conti A, Agnelli G, Berni G. Short-term clinical outcome of patients with acute pulmonary embolism, normal blood pressure, and echocardiographic right ventricular dysfunction. Circulation. 2000;101:2817-22.

27. Harjola VP, Mebazaa A, Celutkiene J, Bettex D, Bueno H, Chioncel O, Crespo-Leiro MG, Falk V, Filippatos G, Gibbs S, et al. Contemporary management of acute right ventricular failure: a statement from the Heart Failure Association and the Working Group on Pulmonary Circulation and Right Ventricular Function of the European Society of Cardiology. Eur J Heart Fail. 2016;18:226-41.

28. Amaral R, Bousquet J, Pereira AM, Araujo LM, Sa-Sousa A, Jacinto T, Almeida R, Delgado L, Fonseca JA. Disentangling the heterogeneity of allergic respiratory diseases by latent class analysis reveals novel phenotypes. Allergy. 2019;74:698-708.

29. Santos AR, Freitas P, Ferreira J, Oliveira A, Goncalves M, Faria D, Bicho Augusto J, Simoes J, Santos A, Gago M, et al. Risk stratification in normotensive acute pulmonary embolism patients: focus on the intermediatehigh risk subgroup. Eur Heart J Acute Cardiovasc Care. 2020;9:279-85.

30. Sanchez O, Trinquart L, Caille V, Couturaud F, Pacouret G, Meneveau N, Verschuren F, Roy PM, Parent F, Righini M, et al. Prognostic factors for pulmonary embolism: the prep study, a prospective multicenter cohort study. Am J Respir Crit Care Med. 2010;181:168-73.

31. Sugiura T, Tanabe N, Matsuura Y, Shigeta A, Kawata N, Jujo T, Yanagawa N, Sakao S, Kasahara Y, Tatsumi K. Role of 320-slice CT imaging in the diagnostic workup of patients with chronic thromboembolic pulmonary hypertension. Chest. 2013;143:1070-7.

32. Roeleveld RJ, Marcus JT, Faes TJ, Gan TJ, Boonstra A, Postmus PE, VonkNoordegraaf A. Interventricular septal configuration at mr imaging and pulmonary arterial pressure in pulmonary hypertension. Radiology. 2005;234:710-7.

33. Lankeit M. Always think of the right ventricle, even in "low-risk" pulmonary embolism. Eur Respir J. 2017;50:1702386.

34. Cote B, Jimenez D, Planquette B, Roche A, Marey J, Pastre J, Meyer G, Sanchez $O$. Prognostic value of right ventricular dilatation in patients with low-risk pulmonary embolism. Eur Respir J. 2017;50:1701611.

\section{Publisher's Note}

Springer Nature remains neutral with regard to jurisdictional claims in published maps and institutional affiliations.
Ready to submit your research? Choose BMC and benefit from:

- fast, convenient online submission

- thorough peer review by experienced researchers in your field

- rapid publication on acceptance

- support for research data, including large and complex data types

- gold Open Access which fosters wider collaboration and increased citations

- maximum visibility for your research: over $100 \mathrm{M}$ website views per year

At BMC, research is always in progress.

Learn more biomedcentral.com/submissions 